\title{
Ocorrência de Úlcera de Abomaso em Bovinos de Leite no Sudoeste do Paraná
}

\author{
Anderson Bedin 1, Alcione Santa Catarina 1, Fabricio Bernardi 1, Marina Gabriela Possa 1, Larisa \\ Gobato 1, Leonardo Gruchouskei 1, Luíz Guilherme Dercore Benevenuto 2, Priscila Emiko Kobayashi 2, \\ Mayane Faccin 3, Carlos Eduardo Fonseca-Alves 2, Fabiana Elias 1
}

${ }^{1}$ Universidade Federal da Fronteira Sul - UFFS, Campus Realeza, Paraná, Brasil.

${ }^{2}$ Faculdade de Medicina Veterinária e Zootecnia, Universidade Estadual Paulista - UNESP, Botucatu, SP, Brasil.

${ }^{3}$ Médica Veterinária autônoma.

*Corresponding author: Carlos Eduardo Fonseca Alves. Rua Dr. Valter Maurício Corrêa, s/n. - Botucatu. Zip Code: 18618-681 - São Paulo, SP, Brasil. E-mail: carlos.e.alves@unesp.br.

Received on: Sep 18, 2021. Accepted on: Oct 14, 2021. Available online: Oct 18, 2021.

\section{Resumo}

A úlcera de abomaso, classicamente definida como um processo de autodigestão da mucosa abomasal, é uma das abomasopatias mais comuns no gado leiteiro. É uma doença multifatorial em que o principal fator desencadeante nem sempre é identificado; estando na maioria das vezes, relacionado com fatores predisponentes. No interesse de fomentar o acervo de informações sobre a ocorrência de abomasopatias, este manuscrito teve como objetivo descrever os aspectos clínicos, epidemiológicos e patológicos dos casos de úlceras de abomaso em bovinos leiteiros diagnosticados na área coberta pela Universidade Federal de Fronteira Sul, Realeza, PR. Foram avaliados 98 casos de bovinos leiteiros do sudoeste do Paraná a partir dos dados de necropsias registrados entre abril de 2009 e dezembro de 2019, de forma retrospectiva, sendo essa lesão relatada em $87,50 \%$ dentre os animais que apresentavam algum tipo de enfermidade digestória ou metabólica. A mediana de vida foi a de 60 meses, sendo apenas 9,52\% criados em sistema intensivo. A ocorrência de úlcera abomasal foi determinante para a morte de 54,17\% dos animais necropsiados que apresentavam enfermidade digestória e/ou metabólica, evidenciando a importância de informação sobre a ocorrência dessa enfermidade, que acomete principalmente o gado leiteiro, podendo levar ao óbito do animal.

Keywords: Úlcera; Abomaso; Epidemiologia; Bovino.

\section{Introdução}

A pecuária leiteira é um setor muito importante para a economia paranaense, em destaque a região sudoeste, que em um período de 10 anos apresentou um crescimento de $98 \%$ na produção colocando a região como principal bacia leiteira do estado [1]. Porém, apesar de a região se apresentar 
em franca expansão na produção leiteira, pouco se sabe sobre as principais afecções que acomete os bovinos.

A partir do momento que houve a busca por incremento na produtividade, a partir da capacidade digestória dos bovinos, houve a necessidade de realizar a seleção genética dos animais, o que resultou em maior susceptibilidade para enfermidades metabólicas e digestórias. No gado leiteiro, as abomasopatias possuem relevante importância, sendo a úlcera de abomaso uma das mais frequentes, a qual é classicamente resultado de um processo de autodigestão da mucosa abomasal de etiologia multifatorial. Existem fatores predisponentes para tal lesão, como por exemplo, fatores alimentares, secundariamente ao deslocamento de abomaso, leucose enzoótica bovina, exposição a situações de estresse e uso prolongado de anti-inflamatórios. A presença de úlcera causa sintomatologia muito variada a depender do grau de acometimento, e seu tratamento é baseado em manobras terapêuticas de manutenção $[2,3,4]$.

Considerando a importância da bovinocultura leiteira e a falta de informações sobre a ocorrência de abomasopatias na região, este trabalho tem como objetivo descrever os aspectos clínicos, epidemiológicos e patológicos de úlceras de abomaso em bovinos leiteiros proveniente da região Sudoeste do Paraná diagnosticados pelo Laboratório de Patologia Veterinária da UFFS, Campus Realeza - PR.

\section{Metodologia}

Local

O estudo foi desenvolvido no laboratório de Patologia da Superintendência Unidade Hospitalar Veterinária Universitária (SUHVU) da Universidade Federal da Fronteira Sul (UFFS), Campus Realeza.

\section{Período}

O estudo foi realizado de forma retrospectiva a partir dos dados de necropsias, registrados no Laboratório de Patologia Veterinária entre abril de 2009 e dezembro de 2019 referentes aos 98 casos de bovinos leiteiros oriundos da região sudoeste do Paraná acometidos por úlcera de abomaso.

Necropsias

Para os exames necroscópicos realizados pelo setor, inicialmente realizava-se a anamnese. Na avaliação externa, era avaliado o estado geral do animal, condição de escore corporal (escala 1:5), presença de ectoparasitas, neoplasias visíveis, coloração das mucosas (vaginal, ocular e cavidade oral), cicatrizes ou lesões evidentes e o exame dos orifícios naturais. Ao exame interno dos cadáveres foi avaliado $\mathrm{O}$ subcutâneo e topografia dos órgãos, os quais foram removidos na forma de bloco e analisados individualmente quanto a superfície externa, tamanho, cor, consistência e superfície de corte.

Para o diagnóstico de úlcera, o abomaso era retirado em bloco com rúmen, retículo e omaso. A abertura das câmaras se deu a partir de suas curvaturas. O abomaso era observado 
quanto a presença de líquidos no lúmen do órgão e presença de erosões, ulcerações, hemorragias ou perfurações.

Exame histopatológico

O exame histopatológico era realizado após a necropsia. Os fragmentos do tecido abomasal acometido foram colhidos, fixados em formalina tamponada $10 \%$ durante 24 horas. Posteriormente, o material passou pelo processamento de rotina para inclusão em parafina, coloração com hematoxilina-eosina e análise histopatológica.

Análise de dados

Os dados foram coletados, tabulados em planilha Excel e analisados de acordo com os seguintes critérios: presença de úlcera de abomaso, ocorrência de enfermidades concomitantes, presença de sinais clínicos sugestivos de úlcera de abomaso, histórico recente de tratamento com anti-inflamatórios não esteroidais, ocorrência de leucose enzoótica bovina e causa mortis.

\section{Resultados}

Dos 98 animais submetidos à necropsia durante o período do estudo, $24(24 / 98 ; 24,49 \%)$ apresentavam algum tipo de enfermidade digestória e/ou metabólica, destes, a úlcera estava presente em 21 casos $(21 / 24 ; 87.50 \%)$. A mediana da idade dos animais afetados foi de 60 meses ( 2 a 144 meses), onde 20 animais $(20 / 21,95,24 \%)$ eram adultos (acima de 1 ano) e um animal (1/21, $4,76 \%)$, tinha 2 meses de idade. As raças encontradas no estudo foram a
Holandesa (14/21), a Jersey (4/21) e Mestiças (3/21), como apresentado na tabela 1. Dezenove animais (19/21; $90,47 \%$ ) eram provenientes de sistemas de criação semi-extensiva a extensiva e apenas $2 / 21(9,52 \%)$ eram criados em sistemas intensivos onde um animal de Free-Stall e outro oriundo de Compost Bar. A presença da úlcera de abomaso foi definida como a causa mortis para 11 animais, dentre os 21 casos onde a úlcera estava presente, representando $52,39 \%$ dos animais acometidos.

Em dez animais (10/21, 47,62\%) a alteração foi relatada como um achado de necropsia, não sendo determinante para morte desses animais (Figura 1). Os principais sinais clínicos observados estão expostos na Tabela 2. Ainda, sinais de choque hipovolêmico estavam presentes em 6 animais (6/21, 28,57\%) e em outros $4(4 / 21,19,05 \%)$ animais, foi identificado peritonite secundária a úlcera perfurada.

Quanto as doenças associadas, em 28,57\% (6/21) dos animais foi descrito histórico de mastite, reticulopericardite e/ou pericardite, em 9,52\% (2/21) houve infecção uterina e em $4,76 \% \quad(1 / 21) \quad$ foi encontrado deslocamento de abomaso. Leucose enzoótica bovina (LEB) foi identificada em $23,80 \%$ dos animais (5/21).

Doze animais (12/21, 57,14\%) não apresentaram histórico de tratamento farmacológico enquanto os outros 9 animais (9/21, 42,86\%) foram submetidos a tratamentos com antiinflamatórios esteroidais e/ou não esteroidais.

Quanto as alterações histológicas, de um modo geral, observaram-se perda 
do epitélio de revestimento, que por vezes, estava com uma discreta camada de fibrina e células polimorfonucleares (Figura 2). A lâmina própria apresentava infiltrado mononuclear com predomínio de linfócitos e plasmócitos. Na submucosa havia edema discreto a moderado, infiltrado intersticial mononuclear difuso leve (Figura 3). Os vasos apresentavam-se congestos. Os animais com diagnóstico de linfossarcoma, além das alterações descritas acima apresentavam também linfócitos neoplásicos associados a lesão.

Tabela 1. Relação das raças, número e porcentagem de bovinos acometidos com úlceras de abomaso no período de abril de 2012 à dezembro de 2018.

\begin{tabular}{|c|c|c|}
\hline Raça & Número & Porcentagem \\
\hline Holandesa & 14 & $66,67 \%$ \\
\hline Jersey & 4 & $19,05 \%$ \\
\hline Mestiça & 3 & $14,28 \%$ \\
\hline Total & 21 & $100 \%$ \\
\hline
\end{tabular}

Tabela 2. Principais sinais clínicos observados em bovinos com úlceras de abomaso diagnosticadas no Laboratório de Patologia Veterinária da Universidade Federal da do Sul.

\begin{tabular}{lcl}
\hline \multicolumn{1}{c}{ Sinal clínico } & Número (n=21) & Porcentagem \\
\hline Apatia & 14 & $66,67 \%$ \\
Redução do ECC & 10 & $47,62 \%$ \\
Diminuição do apetite & 10 & $47,62 \%$ \\
Redução produtividade & 9 & $42,85 \%$ \\
Melena & 8 & $38,09 \%$ \\
Timpanismo & 1 & $4,76 \%$ \\
\hline
\end{tabular}

Legenda: ${ }^{*}$ EC: : Escore de condição corporal.
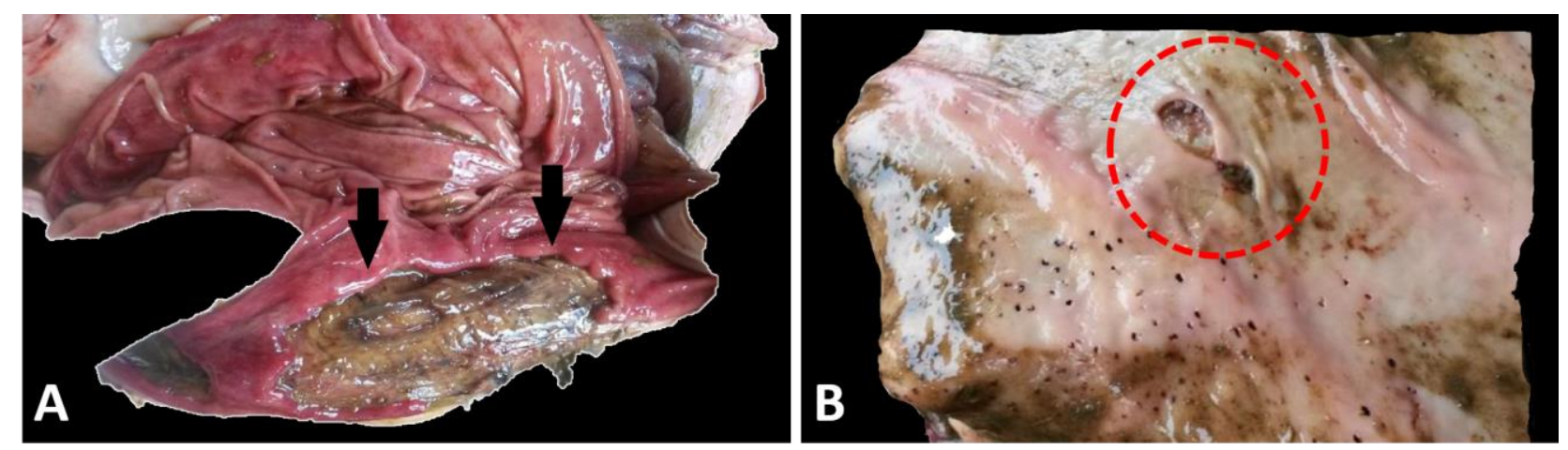

Figura 1 - Alterações macroscópicas do abomaso de bovinos com ceratite ulcerativa. A. Abomaso de bovino com úlcera não perfurada, caracterizada por descontinuidade da mucosa com hemorragia intraluminal. B. Abomaso de outro bovino, apresentando ulceração superficial da mucosa, com áreas de necrose (círculo). 


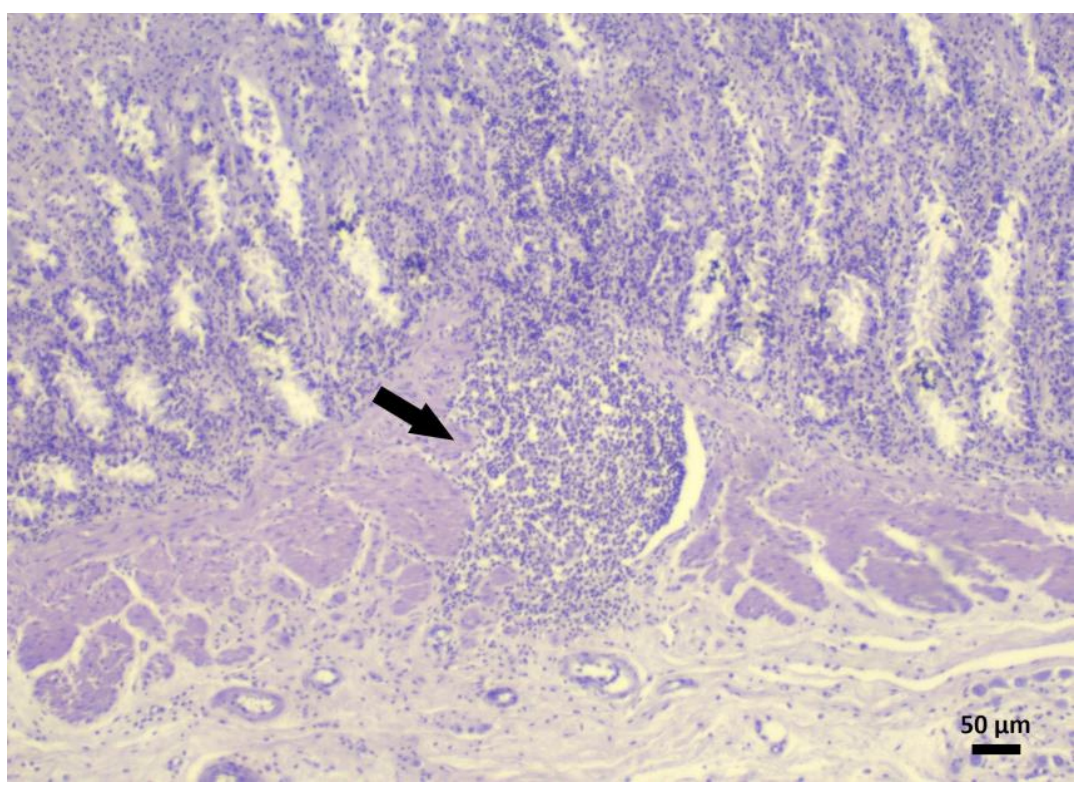

Figura 2. Corte histopatológico evidenciando destruição da camada mucosa e submucosa, com envolvimento da camada muscular (seta) em úlcera de abomaso, com aumento de $5 x$, em H\&E.

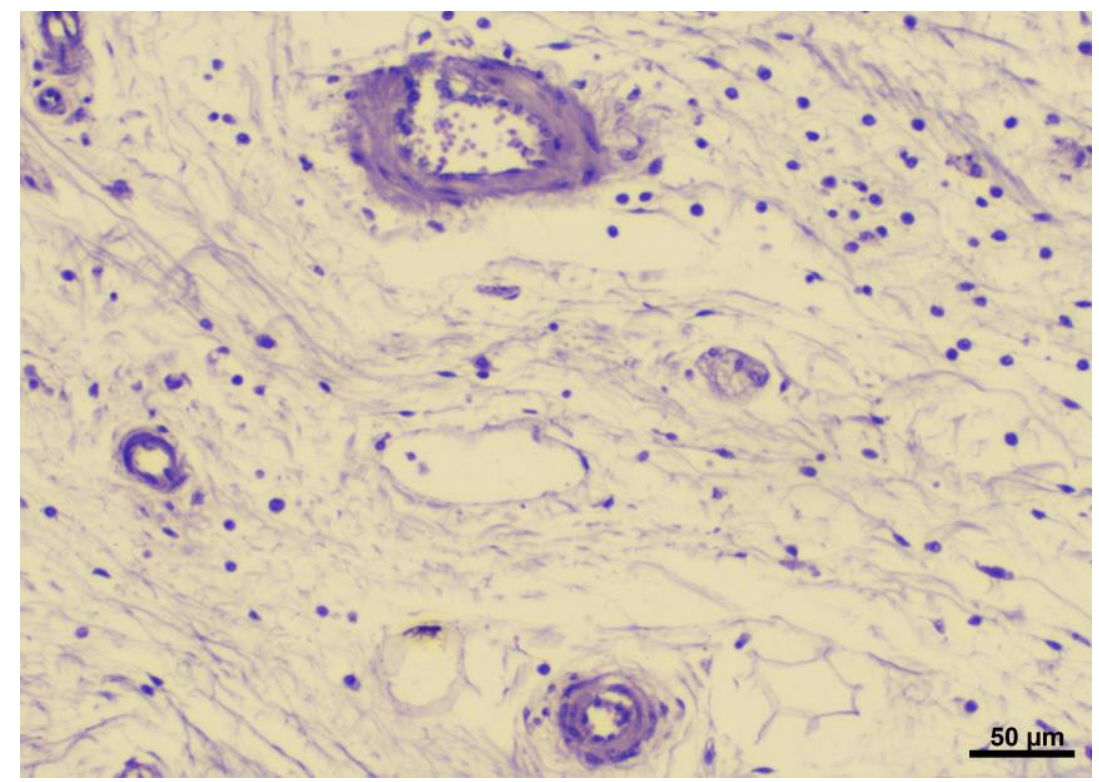

Figura 3 - Corte histopatológico evidenciando edema de submucosa e infiltrado inflamatório mononuclear no abomaso, com aumento de 40x, em H\&E.

\section{Discussão e Conclusão}

O estômago dos ruminantes é composto por quatro compartimentos, rúmen, reticulo, omaso e abomaso. $\mathrm{O}$ abomaso é o compartimento recoberto por mucosa gástrica e onde há produção de ácido clorídrico e pepsinogênio. A alteração da homeostase entre a produção de muco e a produção de ácidos abomasais resultam na formação de úlceras não traumáticas. Estas, são classificadas de acordo com sua gravidade em 4 graus: grau 1 representa 
úlcera não perfurada, com erosão superficial da mucosa e de hemorragia intraluminal mínima; grau 2: lesão mais profunda, porém não perfurada com comprometimento de vasos sanguíneos, causando hemorragia intraluminal significativa; grau 3: lesão com perfuração da parede abomasal e peritonite local e grau 4: lesão com perfuração da parede abomasal, porém com peritonite difusa $[5,6,7,8]$.

Muitos fatores podem predispor ao aparecimento de úlceras e erosões, dentre eles os alimentos grosseiros, estresse ambiental e de manejo, deficiências de vitaminas e minerais e infecções bacterianas [8,9,10]. Além de dietas ricas em grãos, precipitação pluviométrica e adubação das pastagens, os quais irão determinar a qualidade da forrageira e a quantidade de fibra. O uso de anti-inflamatórios não esteroidais, leucose enzoótica bovina e os deslocamentos de abomaso também contribuem para o aparecimento das lesões [11].

As úlceras abomasais acometem bovinos de todas as raças, não havendo predisposição racial. Todavia, no presente estudo observou-se que a raça holandesa representou $66,67 \%$ dos animais, o que corrobora com o rebanho efetivo da região sudoeste do Paraná, onde em $69,44 \%$ dos produtores usam a raça holandesa para a produção de leite, fato explicado pelo alto rendimento dessa raça como produtora de leite [12].

Da mesma forma que não há predisposição racial, animais de ambos os sexos e em todas as idades são acometidos, porém, apresenta-se de forma mais corriqueira em vacas em lactação [3], como observado no presente estudo, onde 95,24\% eram animais adultos. Vacas em lactação possuem maior susceptibilidade as úlceras de abomaso em detrimento ao estresse lactacional e manejo nutricional inadequado [13,14]. Todavia, foi observado a ocorrência de úlcera em um animal com dois meses de idade, similar aos achados de Brasil [15] em 2013, que encontrou prevalência de 1,36 \% em bezerros com idade inferior a um ano de idade na região sul do Rio Grande do Sul. Ainda, Souza et al. [16] em 2016, observou que $50 \%$ (4/8) dos bezerros acometidos por úlcera abomasal apresentavam dois meses de idade. Ambos os autores explicam o acometimento de animais com dois meses de idade estar associado a fatores alimentares, pois este período corresponde ao desmame, em que há transição do alimento lácteo para sólido, com fornecimento de alimentos com $\mathrm{pH}$ ácido como silagem de milho, o que juntamente com funções digestivas não desenvolvidas completamente se tornam um fator predisponente para a ocorrência de úlceras neste período $[15,16]$.

As úlceras de abomaso (hemorrágicas e não hemorrágicas) foram um achado recorrente nas necropsias $(87,50 \%)$ realizadas durante o período de estudo. Os resultados encontrados foram superiores aos encontrados por outros autores, como Carneiro et al. [17] em 2018, que em seu trabalho realizado no Instituto Federal Catarinense no período de 60 meses, encontrou lesão em 16 casos dos 865 bovinos necropsiados representando 
1,85\% dos casos. Ainda, Silva [18] em 2018, em seu estudo retrospectivo de 73 meses não encontrou nenhum caso de úlcera de abomaso nos 311 bovinos necropsiados no hospital veterinário da Universidade Federal da Paraíba.

Quando comparado com outros trabalhos, no presente estudo encontrou-se uma elevada casuística de úlceras em bovinos, o que pode ser explicado pelo fato de que apesar de a região sudoeste do Paraná, a qual está inserida a Universidade Federal da Fronteira Sul - UFFS ser considerada a principal bacia leiteira do Estado, a mesma é caracterizada por pequenas propriedades de agricultura familiar, onde por vezes a ausência de assistência técnica acarretam na falta de informações e conhecimento técnico acerca dos métodos adequados de gestão zootécnica e manejo, contribuindo para a ocorrência da enfermidade [14,19].

No período de estudo, o número de necropsias foi baixo quando comparados com outros autores. Este fato é devido ao exame necroscópico não fazer parte da rotina dos produtores e veterinários e, consequentemente $\mathrm{o}$ diagnóstico é baseado somente nos sinais clínicos. Os sinais clínicos apresentados na úlcera de abomaso podem cursar com outras enfermidades ou estarem associadas a outras doenças, dificultando o diagnóstico definitivo. Portanto, o exame de necropsia se faz muito importante, pois permite um método diagnóstico rápido contribuindo com informações sobre as afecções que acometem os animais da região $[17,18,19,20]$.
A presença de úlcera abomasal foi determinante para a morte de $11,22 \%$ (11/98) dos animais necropsiados e de $54,17 \% \quad(13 / 24)$ dos animais que apresentavam alguma enfermidade de origem digestória e/ou metabólica, nos restantes, a presença de úlcera representou apenas um achado de necropsia. Estes achadas são muito superiores aos encontrados no estudo de Lucena et al. [20] em 2010, onde apenas $0,04 \%$ dos animais vieram a óbito por conta da úlcera de abomaso.

Ulcerações agudas da mucosa abomasal com significativa erosão dos vasos sanguíneos levam ao quadro de gastrite hemorrágica com grandes perdas de volume sanguíneo para o lúmen do órgão, tendo por consequência o choque hipovolêmico [8]. O quadro de hemorragia e consequente choque hipovolêmico foi causa direta na morte de 28,57\% (6/21) dos animais necropsiados com úlcera abomasal. Ainda, a ocorrência de peritonite secundária a úlceras perfuradas, levando ao extravasamento de líquido para cavidade abdominal, foi de $19,05 \%(4 / 21)$.

Considerando o sistema de criação, a ocorrência de úlceras é descrita por acometer mais frequentemente animais criados de forma intensiva [21], porém, 90,47\% $(19 / 21)$ dos animais acometidos neste estudo eram criados de forma semiextensiva a extensiva, sendo apenas $2 / 21$ criados em sistemas intensivos (Um animal de Free-Stall e outro oriundo de Compost Bar). O confinamento de animais é considerado um fator de risco, e aumenta a susceptibilidade dos 
animais perante enfermidades digestórias e metabólicas [13,22], isso pode ser comprovado pelos estudos de Loureiro [23] em 2015, que encontrou $35 \%$ de casuística relacionada a doenças metabólicas em Portugal, onde os sistemas de criação, baseiam-se, principalmente, em sistemas intensivos. Acredita-se que a grande prevalência de animais diagnosticados com úlceras de abomaso no sistema semi-intensivo no presente estudo, seja pela característica da região, onde a agricultura familiar e o sistema semi-intensivo predominam [12].

Quanto a predisposição nutricional, a alimentação rica em carboidratos solúveis a qual são expostas as vacas em lactação, libera grande quantidade de ácidos graxos voláteis e ácido lático favorecendo o aparecimento de úlceras [24]. Também, a mudança na alimentação pode ser considerado um fator de risco, o que se faz uma explicação plausível para as maiores prevalências em estações frias, sabendo-se que, neste período, existe um grande vazio forrageiro na região sul do país, seguida do fornecimento de alimentos altamente fermentáveis como silagem de milho, aveia e azevém, interferindo desta forma, na produção de ácidos do abomaso [24,25].

Doenças do puerpério estão intimamente associadas com a ocorrência de úlcera de abomaso, como deslocamento de abomaso, retenção de placenta, metrite, mastite e cetose, além de repetição de cios e cisto ovariano. No presente trabalho, 28,57\% (6/21) dos animais possuíam histórico de associação com mastite, reticulopericardite e/ou pericardite, em 9,52\% (2/21) houve infecção uterina e em $4,76 \% \quad(1 / 21) \quad$ foi encontrado deslocamento de abomaso. Em seu estudo Villa Filho [14] em 2014, descreveu que 93\% (28/30) dos animais com úlcera de abomaso, apresentavam, concomitantemente, doenças associadas com pós-parto.

Ainda, fatores de estresse desencadeiam o aumento de corticosteroides, podendo aumentar a secreção de ácidos e pepsina no abomaso, predispondo a formação de úlceras [26]. Associado a isto está o uso prolongado do anti-inflamatórios nãoesteroidais [2]. Dos 21 animais acometidos com úlcera de abomaso, 9 possuíam histórico recente de tratamento com uso de antiinflamatórios esteroidais e/ou não esteroidais, o que representou $42,86 \%$ dos casos. Os anti-inflamatórios nãoesteroidais (AINEs) possuem como mecanismo de ação a inibição da COX-2 (ciclooxigenase 2) que são enzimas responsáveis pelo metabolismo do ácido araquidônico em prostaglandinas. Também atuam como mediador próinflamatório e da COX-1 (ciclooxigenase 1), relacionada a produção de prostaglandinas gástricas, as quais agem como agente citoprotetor da mucosa gástrica, inibindo a secreção ácida pelo estômago, aumentando o fluxo sanguíneo na mucosa gástrica e promovendo a secreção de muco citoprotetor. Assim o uso prolongado de AINES diminui as barreiras protetoras da mucosa abomasal predispondo a formação de úlceras [2]. 
A leucose enzoótica bovina foi identificada em 5 animais (23,81\%). Na presença desta enfermidade, frequentemente o sistema digestório é acometido, mais comumente o abomaso, causando obstrução ou úlceras [4]. Em um dos animais acometidos por LEB $(1 / 5)$ a infiltração macroscópica de massas amorfas no abomaso com aspecto esbranquiçado a amarelado, firmes, que variavam de um a vinte centímetros foram responsáveis pela formação das úlceras, uma vez que o crescimento da massa tumoral pode causar isquemia do tecido adjacente, levando a necrose [27].

Em relação as alterações histológicas, as lesões observadas se assemelham aos achados de Souza et al. [28] em 2014, que observou a perda total do epitélio em $87,5 \%$ dos casos de úlcera, por vezes se estendendo até a lâmina própria, com infiltrado inflamatório predominante de neutrófilos acompanhado ou não de congestão vascular.

Devido ao escasso número de estudos sobre o assunto no Brasil e inexistência de informações sobre a região em questão, trabalhos como esse fazem-se necessários para difundir informação sobre a importância e ocorrência da úlcera de abomaso, pois representa uma enfermidade que acomete principalmente o gado leiteiro, podendo levar ao óbito do animal.

\section{Referências}

[1] Mezzadri FP. Situação conjuntural dos últimos anos e prognostico da pecuária. Secretaria de Estado da
Agricultura e do Abastecimento. Departamento de Economia Rural. Dezembro: 01-12. 2018. Disponível em:< http://www.agricultura.pr.gov.br/arquiv os/File/deral/Prognosticos/2019/leite_20 19_v1.pdf>.

[2] Aquino AC, Paiva EC, Couto KM, Rodrigues MGM, Portela AS. O uso de antiinflamatórios não esteroidais (AINEs) e seus efeitos gastrointestinais. Em: Anais do II Congresso Brasileiro de Ciências da Saúde [Internet]; 2017 Junho 01-08; Campina Grande, PB. Disponível em:

http://www.editorarealize.com.br/revist as/conbracis/trabalhos/TRABALHO_EV 071_MD1_SA1_ID2323_15052017215258. pdf

[3] Braun U, Reif C, Nuss K., Hilbe M, Gerspach C. Clinical, laboratory and ultrasonographic findings in 87 cows with type-4 abomasal ulcer. BMC Veterinary Research. 2019;15(100): 01-15.

[4] Jimenez Filho, DL.; Valle CR. Enzootic bovine leukosis - review. J Chem Inf Model. 2013;53(9):1689-99.

[5] Braun U, Reif C, Nuss K., Hilbe M, Gerspach C. Clinical, laboratory and ultrasonographic findings in 87 cows with type-4 abomasal ulcer. BMC Veterinary Research. 2019;15(100): 01-15.

[6] Hund A, Dzieciol M, Schmitz-Esser $S$, Wittek T. Characterization of mucosaassociated bacterial communities in abomasal ulcers by pyrosequencing. Vet Microbiol [Internet]. 2015;177(1-2):13241. Disponível em: http://dx.doi.org/10.1016/j.vetmic.2015.0 2.023 
[7] Hussain SA, Uppal SK, Sood NK. The prevalence, frequency and topographic distribution of type 1 abomasal ulcers in water buffalo (bubalus bubalis): A case control study. Vet Arh. 2019;89(3):317-30

[8] Marshall TS. Abomasal Ulceration and Tympany of Calves. Vet Clin North Am - Food Anim Pract. 2009;25(1):20920. Disponível em: http://dx.doi.org/10.1016/j.cvfa.2008.10.0 10

[9] Mills KW, Jensen RL, Woodard LF, Johnson JL, Doster AR. Laboratory Findings Associated with Abomasal Ulcers/Tympany in Range Calves. J Vet Diagnostic Investig. 1990;2(3):208-12.

[10] Niehaus AJ. Surgery of the Abomasum. Vet Clin North Am - Food Anim Pract. 2008;24(2):349-58.

[11] Radostits OM, Gay CC, Blood, DC, Hinchcliff KW. Um tratado de doenças dos bovinos, ovinos, suínos, caprinos e equinos. 9. Ed. Rio de Janeiro: Guanabara Koogan; 2002;9: 302-305 p.

[12] Vieira V da C, Moro V, Farinacio D, Martin TN, Menezes LFG de. Caracterização da silagem de milho, produzida em propriedades rurais do sudoeste do Paraná. Rev Ceres. 2011;58(4):462-9.

[13] Hansen LB. Consequences of selection for milk yield from a geneticist's viewpoint. J Dairy Sci [Internet]. 2000;83(5):1145-50. Disponível em: http://dx.doi.org /10.3168/jds.S0022-0302(00)74980-0

[14] Villa Filho PC. Utilização De Omeprazol Em Vacas Leiteiras Com
Presença De Sangue Oculto Nas Fezes. Util omeprazol em vacas leiteiras com presença sangue oculto nas fezes. 2014;17. Disponível em: https://repositorio.unb.br/handle/10482/ 16824

[15] Brasil ND, Pereira CM, Hinnah FL, Ladeira SRL, Sallis ESV, Grecco FB, Schild AL. Enfermidades diagnosticadas em bezerros na região sul do Rio Grande do Sul. Pesquisa Veterinária Brasileira. 2013;33(4):423-430.

[16] Souza LM, Assis RN, Rego RO, Dos Santos JF, Coutinho, LT, Souza JCA, Mendonça CL, Afonso JAB, Souto RJC. Achados clínicos, laboratoriais e anatomopatológicos de bezerros com úlceras de abomaso. Ciência Veterinária nos Trópicos. 2016;19(3):20-28.

[17] Carneiro C, Schwertz CI, Henker LC, Rhoden LA, Piva MM, Gabriel ME, Lucca NJ, Baldi KRA, Casagrande RA, Gomes TMA, Mendes RE. Doenças Diagnosticadas no Laboratório de Medicina Veterinária no Quinquênio 2013 - 2017. Boletim Diagnóstico do Laboratório de Patologia Veterinária. 2018;2(1): $01-16$.

[18] Silva M.C.S. Estudo Retrospectivo das Enfermidades de Ruminantes Diagnosticadas no Hospital Veterinário da Universidade Federa da Paraíba. Paraíba. 2018 Novembro 01-33.

[19] Sprenger LK, Risolia LW, Gabardo LB, Molento MB, Silva AWC da, Sousa RS de. Doenças de ruminantes domésticos diagnosticados no laboratório de patologia veterinária da Universidade Federal do Paraná: 1075 casos. Arch Vet Sci. 2012;17(4):63-9. 
[20] Lucena RB, Pierezan F, Kommers GD, Irigoyen LF, Fighera RA, Barros CSL. Doenças de bovinos no Sul do Brasil: 6.706 casos. Pesqui Vet Bras. 2010;30(5):428-34

[21] Ducharme NG, Fubini SL, Pease AP, Trent AM, Steiner A. Surgery of the Bovine Digestive System. Elsevier Inc. In Farm Animal Surgery (pp. 161-175). Disponível em: https://doi.org/10.1016/B0-72-1690629/50014-9

[22] Radostits OM, Gay CC, Hinchcliff $\mathrm{KW}$, Constable PD. Diseases of the alimentary tract: a textbook of the diseases of cattle, horses, sheep, pigs and goats. 11. Ed. Saunders ltd; 2016;10:236-310 p.

[23] Loureiro MAP. Clínica e reprodução de bovinos de leite [master's thesis]. Portugal: Curso de Mestrado Integrado de Medicina Veterinária, Universidade de Évora; 2015. 108 p.

[24] Silva Filho AP., Afonso JAB, Costa NA, Souza JCA, Dantas AC, Mendonça CL. Achados clínicos de bovinos com úlcera de abomaso. Veterinária e Zootecnia. 2012;19(2):196-206.

[25] Andrews AH, Blowey RW, Boyd H, Eddy RG. Medicina Bovina Doenças e Criação de Bovinos. 2. Ed. Barueri: Roca; 2008. 1080 p.

[26] Borges JRJ, Moscardini ARC. Úlcera de abomaso. Em: Riet-Correa F., Schild A.L., Lemos R.A.A., Borges J.R.J. (Eds). Doenças de Ruminantes e Equídeos. 3.ed. Palotti: Santa Maria, 2007; pp.367370.
[27] Hund A, Wittek T. Abomasal and Third Compartment Ulcers in Ruminants and South American Camelids. Vet Clin North Am - Food Anim Pract. 2018;34(1):35-54. Disponível em: https://doi.org/10.1016/j.cvfa.2017.10.003 [28] de Souza MV, Da Costa MBM, Pinto J de O, Da Silva JCP, Dantas Ribeiro Filho J, Moreira J do CL. Lesões gástricas em equinos de abatedouro: Avaliação macroscópica e histological. Cienc Rural. 2014;44(9):1622-8.

Conflitos de interesses: Os autores declaram não haver conflitos de interesse.

Agradecimentos: None.

Financiamentos: None.

Como citar este artigo: Bedin A, Catarina AS, Bernardi F, Possa MG, Gobato L, Gruchouskei L, Benevenuto LGD, Kobayashi PE, Faccin M, FonsecaAlves CE, Elias F. Ocorrência de Úlcera de Abomaso em Bovinos de Leite no Sudoeste do Paraná. Brazilian Journal of Case Reports. 2021 Jul-Sep;01(4):57-67. 